Keywords: PTSD; MDE; Comorbidity; Palestine; Mass violence.

\title{
Posttraumatic stress disorders comorbid with major depression in West Bank, Palestine: a general population cross sectional study
}

\author{
Michael G. Madianos, MD MPH* \\ Adnan Lufti Sarhan, RN MSc ${ }^{\star *}$ \\ Evmorfia Koukia, RN MSc* \\ * Department of Mental Health and \\ Behavioral Sciences, Faculty of Nursing, \\ School of Health Sciences, University \\ of Athens \\ ** Faculty of Nursing, An-Najah National \\ University, Nablus \\ GREECE \\ PALESTINE
}

\begin{abstract}
Background and Objectives: The prevalence of Post Traumatic Stress Disorders (PTSD) comorbid with Major Depressive Episodes (MDE) were explored in four areas of West Bank of Palestine in the aftermath of the second intifada.

Methods: The sample consisted of 916 adult Palestinians representative of the general population. The interview was personal with the use of DSM IV criteria for PTSD and MDE (the SCID I modules).

Results: The prevalence of chronic PTSD comorbid with lifetime MDE and chronic PTSD alone were found $18.7 \%$ and $26.5 \%$ respectively. Another $6.1 \%$ were diagnosed as suffering from lifetime MDE. Higher numbers of refugees were found to suffer from PTSD comorbid with MDE. The majority of respondents who reported previous suicidal behavior were comorbid cases of PTSD/MDE. The predictors differentiating between MDE alone and no diagnosis and between comorbid PTSD/MDE and no diagnosis were almost identical.

Conclusions: This sample of adult Palestinians living under conditions of mass violence and continuous economic deprivation were found suffering from high rates of post PTSD and comorbid PTSD with MDE, a common finding among populations under serious traumatic exposure.
\end{abstract}


In the epidemiology of Posttraumatic Stress Disorder (PTSD) both clinical and general population surveys have shown that the majority of respondents who have been exposed in serious traumatic experiences and diagnosed as suffering from PTSD, meet the criteria for at least one other psychiatric disor$\operatorname{der}^{1-5}$. Breslau et al. ${ }^{2}$, reported that $83 \%$ of the diagnosed individuals as suffering from PTSD met criteria for at least one other psychiatric disorder. In the National Comorbidity Study ${ }^{4} 88 \%$ of males and $79 \%$ of females respondents with chronic PTSD, had another psychiatric diagnosis.

In the Australian National Survey of Mental Health and Well-Being, $85 \%$ of the males with PTSD and $80 \%$ of females were also found to meet the criteria for another DSM IV disorder for the past year ${ }^{6}$. One of the most frequent comorbid psychiatric disorder with lifetime PTSD, is the Major Depressive Episode (MDE) $)^{3-5,7-11}$. PTSD and depressive symptoms occur frequently, following exposure to a traumatic event or events.

In the studies by Breslau et al. ${ }^{2}$, Kessler et al. ${ }^{4}$ and Creamer et al. ${ }^{6}$ the most frequent psychiatric disorder comorbid with PTSD was found to be major depression. Additionally PTSD increases the risk of suicidal behavior $^{12-14}$.

The association between major depression including suicidality and PTSD could be explained by the possible triggering of onset of depression though the mechanism of trauma and vulnerability ${ }^{4,15}$. The preexistence of depressive symptomatology may also contribute to the incidence of PTSD after exposure to traumatic events ${ }^{16}$.

In population under acute stress namely refugees, war veterans, victims of disasters (natural or manmade) or entire populations living in long lasting conflict zones, the rates of PTSD comorbid with MDE reported by several investigators, are higher than those recorded in general population surveys ${ }^{1,17-22}$. For example Marshall et al. ${ }^{23}$ reported that $71 \%$ of Cambodian refugees, two decades after their resettlement in USA, met the criteria for MDE and $86 \%$ of those with major depression, met also criteria for PTSD.

Palestine of West Bank of Jordan River and Gaza strip is the case of a country with high volume of a variety of sociopolitical adversities, duration of unresolved conflict and high volume of mass violence ${ }^{24,25}$. In adults, there were two studies on the prevalence of PTSD in a general population sample, both carried out in Gaza strip. In the first study focusing on gender specific trauma exposure and mental health symptoms among Palestinians living in Gaza strip conditions of military violence, $24 \%$ of males and $16 \%$ of females were diagnosed as suffering from PTSD by the use of PTSD module of CIDI schedule ${ }^{26}$. However the investigators did not provided data on comorbidity. In the second study on the prevalence of PTSD by the use also of CIDI, in countries facing mass violence (Algeria, Cambodia, Ethiopia and Gaza strip), the rates of PTSD found in the Gaza sample reached $28.4 \%$ the males reported more PTSD symptoms than females ${ }^{27}$. No data on comorbidity with major depression were also given. Finally, in the neighboring Lebanon, the effect of war events on the prevalence of major depression was examined by the application of D.I.S. schedule, and provided rates ranging from $16.3 \%$ to $41.9 \%$ with no reference to any comorbidity findings ${ }^{28}$.

In a recent study by Elbedour et al. ${ }^{29}$, among Palestinian adolescents 12 to 18 years old, following the second intifada (uprising) of 2000-2007 in Gaza strip, 68.9\% were classified as having developed PTSD and $40.0 \%$ reported moderate or severe levels of depression. PTSD was assessed by specific instrument with criteria-symptoms 
matching with those of DSM IV of APA. It should be mentioned that during this period more than 30.000 Palestinians suffered from moderate or serious injuries. Finally Kha$\mathrm{mis}^{30}$, in her study among injured Palestinian adolescents, reported that $76.5 \%$ of them had a DSM IV diagnosis of PTSD with chronic symptoms and comorbid with depression and anxiety.

To our knowledge no systematic clinicoepidemiological study has ever been conducted in the adult general population of West Bank, to explore the dimensions of PTSD, MDE and the related comorbidity.

The current study was carried out 1) to explore the dimensions of comorbidity of PTSD with MDE in a general population sample of Palestinians of West Bank at the end of second "intifada" 2) to investigate the prevalence of comorbidity of PTSD and MDE among those Palestinians were identified as refugees 3 ) to examine the suicidal behavior among each diagnostic category and 4) to delineate the possible differences in predictors of categorical diagnosis of PTSD, MDE and comorbid PTSD/MDE.

\section{Method}

\section{Participants}

The study was based on a multistage sample of Palestinians aged 20-65 residing in four geographical areas, two in the north of West Bank (Tulkarm and Jenin) one in the middle (Rammalah) and one in the south (Bethlehem). The sample was drawn from three different locations, towns, villages and refugees camps of each geographical areas.

The sample involved a probability random selection of households within the selected neighborhoods, across the four geo- graphic areas, covering a total of 850,450 inhabitants, with an adult population of 387,000 . There was a household to household selection across each area dwelling blocks (neighborhoods) housing at least of one resident. The neighborhoods in the three different study locations (town, village or camp) were randomly assigned. The interviewer used random lists of blocks. Each block was selected according to their spatial distribution and density. Finally the interviewer used a random number list to select one subject from the household who fulfilled the selection criteria such as age (20-70 years) and gender. The criterion for exclusion was the severe cognitive impairment. The number of eligible households in all areas was 102,802 and the number approached was 1,108 .

The final sample comprised 916 individuals agreeing to give their consent for their participation in the study. Refusal rate was found to be $8 \%$. The sample size in each of the four areas was 1/1000 inhabitants. The proportion $(\%)$ of age clusters by gender of the sample and the corresponding age groups of the local general population were almost identical. The proportions \% of age groups 20-29 and 30-39 of the sample were $26.9 \%$ and $29.1 \%$ respectively compared to those of the general population census of $31.1 \%$ and $29.5 \%$. For the rest of the age groups of 40-49, 50-59 and above 60, were found to be $17.3 \%, 16.5 \%$ and $10.0 \%$, corresponding to $18.0 \%, 16.8 \%$ and $10.3 \%$ of the general population respectively.

\section{Procedures}

The interview was anonymous and carried out by the second of the authors, native of the town of Tulkarm, face to face from February to September 2007. The data collection process started and ended during the 
effect of the (AlAqsa) "intifada". Completion of interview required 60 minutes with an average of 40 minutes. The interviewer completed training in the use of the clinical interview with a series of pilot interviews with Arab origin psychiatric outpatients in Athens. The questionnaire was structured in three parts including social demographic data and clinical interview.

The diagnosis of lifetime and one month Major Depression and Post Traumatic Stress Disorder was made possible by the application of the relevant modules of the Structured Clinical Interview for DSM IV ${ }^{31}$.

This part was translated back into English by a bilingual Arab. The items were translated back into English matched to the origin version. Suicidal behavior comprised of information on suicidal ideation, drawn from the relevant module of SCID Axis I and any previous suicidal attempt detected through a supplementary question.

The reliability of DSM IV criteria for Major Depression Episode was tested by the clinical examination of 50 outpatients being of Arab origin, attending an outpatient psychiatric clinic in Athens, by two independent raters, being an Arab speaking psychiatrist and the second of the authors. Out of these patients 32 and 29 were diagnosed as suffering from major depression by raters $\mathrm{A}$ and $B$ respectively. The estimation of their agreement which was found to be $\mathrm{k}$ coefficient $0.87, \mathrm{z}: 12.00 \mathrm{P}<0.001$ meaning that the interrater reliability of DSM IV criteria for Major Depressive Episode was high.

For the establishment of a PTSD diagnosis the individuals who were found to suffer from two symptoms from criterion $\mathrm{A}$, one or more out of five, in criterion $\mathrm{B}$, three or more out of five in the last criterion $\mathrm{D}$, were diagnosed as having PTSD. Cases of partial of subthreshold PTSD were excluded from the analysis. Duration of the disorder was also explored accordingly.

The alpha coefficient reliability of the nineteen PTSD symptoms schedule was 0.89 denoting high internal consistency. The interrater reliability of DSM IV criteria for PTSD was tested by the clinical examination of 50 psychiatric outpatients of Arab origin being refugees by two independent raters one Arab speaking psychiatrist and the second of the authors. Out of these patients thirteen were diagnosed as suffering from PTSD by both the clinical raters, a $100 \%$ agreement.

\section{Detection of comorbidity}

The respondents who met the diagnostic criteria for both diagnoses of lifetime Major Depressive Episode and chronic Post Traumatic Stress Disorder were identified as comorbidity cases of PTSD with MDE.

\section{Data analysis}

For all two -by two tables, chi-square values are shown. Possible differences in predictors were explored by the application of multinomial logistic regression, among the respondents with Major Depression (lifetime) alone Post Traumatic Stress Disorder (chronic) alone and comorbid PTSD/ Depression in comparison with the respondents with no diagnosis. This method was chosen because the dependent variable (diagnosis) had more than two categories. The possible predictors to be included in this analysis were the following: gender, age, occupational and marital status, income, place of residence, type of home, social status, suicidal behavior, previous help-seeking and use of psychotropics.

Statistical analyses were performed with SPSS $15.0^{32}$. 


\section{Results}

Table 1 displays the sociodemographics of the samples by gender. The ratio of males/ females was about $1: 1$ and $64.5 \%$ of them were married (almost in equal proportion among sexes). With respect to the occupation and place of residence, $34 \%$ were found to be employees in the public sector of Palestinian Authority and $38.3 \%$ were residents of villages as well as $31.2 \%$ were living in refugee camps. A $33.2 \%$ had no income dependent on welfare benefits. Women were found to work at home (housekeeping) at greater extend than men.

The mean age of the sample was found to be $39.71 \pm 17.0$.

Table 1

Sociodemographic characteristics by gender (n: 916)

\begin{tabular}{|c|c|c|c|c|c|c|c|}
\hline & & \multicolumn{2}{|c|}{ Males } & \multicolumn{2}{|c|}{ Females } & \multicolumn{2}{|c|}{ Total } \\
\hline & & $\mathrm{N}$ & $\%$ & $\mathrm{~N}$ & $\%$ & $\mathrm{~N}$ & $\%$ \\
\hline Gender & & 455 & 49.7 & 461 & 50.3 & 916 & 100.0 \\
\hline \multirow[t]{5}{*}{ Marital status } & Single & 136 & 29.9 & 140 & 30.4 & 276 & 30.0 \\
\hline & Married & 310 & 68.1 & 279 & 60.5 & 589 & 64.5 \\
\hline & Divorced & 1 & 0.2 & 17 & 3.7 & 18 & 2.0 \\
\hline & Widow & 8 & 1.8 & 25 & 5.4 & 33 & 3.5 \\
\hline & & 455 & 100.0 & 461 & 100.0 & 916 & 100.0 \\
\hline \multirow[t]{5}{*}{ Place of residence } & Town & 138 & 30.3 & 143 & 31.0 & 281 & 30.5 \\
\hline & Village & 174 & 38.3 & 176 & 38.2 & 350 & 38.3 \\
\hline & Refugee & 143 & 31.4 & 142 & 30.8 & 285 & 31.2 \\
\hline & Camp & & & & & & \\
\hline & & 455 & 100.0 & 461 & 100.0 & 916 & 100.0 \\
\hline \multirow[t]{5}{*}{ Occupation } & Employees & 171 & 37.6 & 145 & 31.5 & 316 & 34.5 \\
\hline & Workers & 159 & 34.9 & 31 & 6.7 & 190 & 20.8 \\
\hline & Students & 53 & 11.6 & 79 & 17.1 & 132 & 14.4 \\
\hline & Other & 72 & 15.9 & 206 & 44.7 & 278 & 30.3 \\
\hline & & 455 & 100.0 & 461 & 100.0 & 916 & 100.0 \\
\hline \multirow[t]{5}{*}{ Income } & No income & 107 & 23.5 & 197 & 42.7 & 304 & 33.2 \\
\hline & $<300 \$$ & 166 & 36.5 & 125 & 27.1 & 291 & 31.7 \\
\hline & $300-600 \$$ & 136 & 29.9 & 123 & 26.7 & 259 & 28.3 \\
\hline & $>600 \$$ & 46 & 10.1 & 16 & 3.5 & 62 & 6.8 \\
\hline & & 455 & 100.0 & 461 & 100.0 & 916 & 100.0 \\
\hline \multirow[t]{3}{*}{ Social Status } & Refugee & 216 & 47.5 & 257 & 55.7 & 473 & 51.5 \\
\hline & Non refugee & 239 & 52.5 & 204 & 44.3 & 443 & 48.5 \\
\hline & & 455 & 100.0 & 461 & 100.0 & 916 & 100.0 \\
\hline
\end{tabular}


Table 2

Lifetime prevalence (\%) of PTSD and PTSD with MDE and cases of MDE among West Bank Palestinians (n: 916)

\begin{tabular}{|c|c|c|c|c|c|c|c|c|c|c|c|c|c|}
\hline \multirow[t]{2}{*}{ Gender } & \multicolumn{4}{|c|}{ Non cases } & \multicolumn{3}{|c|}{$\mathrm{PTSD}^{1}$} & \multicolumn{3}{|c|}{$\mathrm{PTSD} \mathrm{MDE}^{2}$} & \multicolumn{3}{|c|}{$\mathrm{MDE}^{2}$} \\
\hline & $\mathrm{N}$ & $\%$ & $\mathrm{~N}$ & $\%$ & $\mathrm{~N}$ & $\%$ & S.E. & $\mathrm{N}$ & $\%$ & S.E. & $\mathrm{N}$ & $\%$ & S.E. \\
\hline Males & 455 & 100.0 & 209 & 45.9 & 125 & 27.5 & 1.6 & 82 & 18.0 & 0.9 & 39 & 8.6 & 0.8 \\
\hline Females & 461 & 100.0 & 237 & 51.4 & 118 & 25.6 & 1.3 & 89 & 19.3 & 1.1 & 17 & 3.7 & 0.6 \\
\hline Total & 916 & 100.0 & 446 & 48.7 & 243 & 26.5 & 1.5 & 171 & 18.7 & 0.9 & 56 & 6.1 & 0.7 \\
\hline
\end{tabular}

The prevalence of comorbidity with cases of PTSD and cases of MDE is shown in table 2 .

A $26.5 \%$ of the sample was found to suffer from PTSD. Additionaly $18.7 \%$ and $6.1 \%$ were found to have developed PTSD comorbid with MDE and MDE alone respectively. Males have shown a higher degree of psychiatric morbidity than females.

Regarding chronicity (criterion E), all respondents of group A of both sexes who were diagnosed as cases of PTSD, reported that they had the PTSD symptoms for more than three months (chronic PTSD). In that way these cases were tested if they fulfilled the criteria for a lifetime MDE.

At the time of interview, 97 respondents (52 males and 45 females) $10.6 \%$ of the sample, met the criteria for a current (last 30 days) MDE. All of them met also the criteria for a chronic PTSD. Criterion F (was assessed by the use of a specific question on functioning level in the areas of roles e.g. parenting housekeeping work and recreation. All the cases meeting the other criteria they have met also this criterion.

There were more PTSD criteria symptoms endorsed in the comorbid group ( $\mathrm{x}$ : $12.63 \pm 5.01)$ than among the non comorbid
PTSD cases (x $11.54 \pm 4.82)$ a statistically significant difference (data not shown).

The prevalence rates of PTSD, PTSD/ MDE and MDE were found to be almost equally distributed among the sample respondents drawn from towns, villages and refugee camps.

The comparison of comorbid cases of PTSD/MDE among the refugees and non refugees are presented in table 3 .

Apparently higher proportion refugees Palestinians were diagnosed as having chronic PTSD comorbid with lifetime MDE compared to that of their non refugees counterparts. The diagnostic categories among the two group were found to differ at statistically significant difference $(\mathrm{p}<0.001)$.

The prevalence of reported suicidal behavior (attempted suicides) in relation to diagnostic categories is shown in table 4 .

Among the males out of the 39 who reported that they have previously attempted suicide, twenty of them were diagnosed as comorbid cases of PTSD/MDE.

In females lower number ${ }^{23}$ than their males counterparts reported previous suicidal behavior, and the majority of them have also been identified as comorbid cases. The com- 
Table 3

Prevalence (\%) of chronic PTSD and comorbid chronic PTSD with lifetime $\mathrm{MDE}^{1}$ among refugees and non refugees of West Bank Palestinians

\begin{tabular}{lrrrrrrrrr} 
Diagnosis & \multicolumn{3}{c}{ Refugees } & \multicolumn{3}{c}{ Non Refugees } & \multicolumn{3}{c}{ Total } \\
\hline Cases of PTSD & $\mathrm{N}$ & $\%$ & S.E. & \multicolumn{1}{c}{$\mathrm{N}$} & $\%$ & S.E. & $\mathrm{N}$ & $\%$ & S.E. \\
\hline Cases of PTSD/MDE & 121 & 25.6 & 1.3 & 122 & 27.5 & 1.6 & 243 & 26.5 & 1.5 \\
\hline MDE & 120 & 25.4 & 1.3 & 51 & 11.5 & 9.0 & 171 & 18.7 & 1.2 \\
\hline Non Cases & 29 & 6.1 & 0.7 & 27 & 6.2 & 0.6 & 56 & 6.1 & 0.6 \\
\hline Total & 203 & 42.9 & 2.5 & 243 & 54.8 & 3.0 & 446 & 48.7 & 2.8 \\
\hline
\end{tabular}

$\mathrm{X}^{2}: 30.55 \quad$ df: $3 \quad \mathrm{P}<0.001$

${ }^{1}$ lifetime prevalence.

Table 4

Prevalence (\%) of previous suicide attempts by diagnostic categories among West Bank Palestinians (n: 916)

Males

Females

\begin{tabular}{lcccccccccccccccc}
\hline & \multicolumn{3}{c}{ Suicide attempts } & \multicolumn{1}{c}{ Suicide attempts } \\
\hline $\begin{array}{l}\text { Diagnostic } \\
\text { Categories }\end{array}$ & \multicolumn{4}{c}{ YES } & \multicolumn{1}{c}{ NO } & & & YES & & NO & $\begin{array}{c}\mathrm{X}^{2} \\
\text { yates }\end{array}$ & Sign. \\
\hline & $\mathrm{N}$ & $\%$ & $\mathrm{~N}$ & $\%$ & $\mathrm{~N}$ & $\%$ & $\mathrm{~N}$ & $\%$ & $\mathrm{~N}$ & $\%$ & $\mathrm{~N}$ & $\%$ & corr. \\
\hline PTSD & 125 & 100.0 & 4 & 3.2 & 121 & 96.8 & 118 & 100.0 & 7 & 5.9 & 111 & 94.1 & 2.00 & N.S \\
\hline PTSD/MDE & 82 & 100.0 & 20 & 24.4 & 62 & 75.6 & 89 & 100.0 & 9 & 10.1 & 80 & 89.9 & 9.25 & P $<0.01$ \\
\hline MDE & 39 & 100.0 & 15 & 38.5 & 24 & 61.5 & 17 & 100.0 & 7 & 41.2 & 10 & 58.8 & 0.11 & N.S \\
\hline Total & 246 & 100.0 & 39 & 15.8 & 207 & 84.2 & 224 & 100.0 & 23 & 10.2 & 201 & 89.8 & 3.70 & N.S \\
\hline
\end{tabular}

parison of suicide attempts among males and females diagnosed as having PTSD, PTSD/ MDE and MDE alone has shown a statistically significant difference $(\mathrm{p}<0.01)$ only in the category of comorbid cases.

Finally the application of multinomial logistic regression used to explore possible differences in predictors among respondents with chronic PTSD, lifetime MDE and comorbid PTSD/MDE with respondents with no diagnosis.
A number of eleven independent variables were entered in the analysis. Two variables marital status and attempted suicide were found to differentiate depression alone from non diagnosis.

Place of residence, social status (refugee non refugee) and use of psychotropic medication differentiate PTSD from no diagnosis. The same predictors and additionally marital status differentiated comorbid PTSD/MDE from non diagnosis, at statistically significant levels. 
Table 5

Diagnostic predictors among west-Bank Palestinians (n: 916)

Likelihood of diagnosis relative to no diagnosis

\begin{tabular}{lcccccc}
\hline & \multicolumn{2}{c}{ MDE* $^{*}$} & \multicolumn{2}{c}{ PTSD } & \multicolumn{2}{c}{ PTSD/MDE* } \\
\hline Variables & Odds ratio & $95 \%$ CI & Odds ratio & $95 \%$ CI & Odds ratio & $95 \%$ CI \\
\hline Gender & 0.76 & $0.33-1.26$ & 0.69 & $0.13-1.26$ & 0.93 & $0.58-1.44$ \\
\hline Age & 1.03 & $0.92-1.37$ & 0.98 & $0.45-1.67$ & 1.18 & $0.32-1.55$ \\
\hline Occupation & 1.10 & $0.80-2.30$ & 1.09 & $0.49-1.88$ & 1.05 & $0.40-1.49$ \\
\hline Marital status & $1.25^{2}$ & $0.80-1.98$ & 0.93 & $0.44-1.91$ & 0.63 & $0.17-1.30$ \\
\hline Income & 0.90 & $0.76-1.86$ & $1.61^{2}$ & $0.53-2.40$ & 0.89 & $0.53-1.39$ \\
\hline Place of Residence & 0.86 & $1.29-2.16$ & $1.85^{2}$ & $0.42-2.75$ & 1.07 & $0.34-2.50$ \\
\hline Type of home & 0.91 & $0.48-2.49$ & 0.74 & $0.22-1.25$ & 0.86 & $0.46-1.28$ \\
\hline Refugees/Non refugees & $2.10^{1}$ & $0.66-4.00$ & 0.79 & $0.37-3.31$ & $2.13^{1}$ & $1.33-2.77$ \\
\hline Attempted suicide & $1.35^{2}$ & $0.65-1.99$ & 1.14 & $0.37-2.90$ & $1.21^{1}$ & $0.71-1.73$ \\
\hline Previous Helpseeking & -1.06 & $0.84-1.49$ & 0.60 & $0.29-1.90$ & 0.86 & $0.48-1.67$ \\
\hline Use of psychotropics & $2.18^{1}$ & $0.58-3.18$ & 0.90 & $0.66-1.32$ & $3.01^{1}$ & $1.35-6.80$ \\
\hline
\end{tabular}

* Lifetime prevalence.

${ }^{1}: \mathrm{P}<0.01$

2: $\mathrm{P}<0.05$

\section{Discussion}

In this population of severely exposed to mass violence and trauma, at the end of the second uprising (intifada), the proportion of respondents meeting full diagnostic criteria for chronic PTSD and lifetime MDE as well as PTSD/MDE was found to be $51.3 \%$. The prevalence of comorbid PTSD with MDE was found to be $18.7 \%$. This finding is consistent with the ones reported by other investigators $^{3-5,7-11}$.

In the National Comorbidity Study $48 \%$ of the general population with a chronic PTSD also fulfilled the criteria for a lifetime MDE. In another study among victims of a natural disaster $32 \%$ of the survivors had PTSD and MDE and 53\% of them with
PTSD had comorbid MDE ${ }^{33}$. Breslau et al. ${ }^{7}$ also reported that $47.9 \%$ of persons with a lifetime PTSD had a lifetime MDE. Kulka et al. ${ }^{1}$ found similar prevalence rates among Vietnam veterans suffering from PTSD.

In their study during the time of "intifada" focusing on the prevalence PTSD and Depression in a sample of Palestinian adolescents in West Bank, Elbedour et al. ${ }^{29}$, found that $68.9 \%$ and $40 \%$ to have developed PTSD and Depression respectively.

It is evident that the continuous exposure to series of chronic recurrent traumatic events, including somatic injuries, the atmosphere of fear, terror, hopelessness for the future and helplessness and the extreme deprivation of economic resources, with unemployment rates exceeding 50\% are "fer- 
tilizing" the symptoms of PTSD and Depression. The latter is a common outcome of trauma exposure and is often comorbid with PTSD. In our study only a $10.6 \%$ of the sample was identified as suffering from recent onset (one month) MDE although they were suffering long before from PTSD. Apparently, post-trauma MDE occurred through possible additive mechanism.

The clinical boundaries between the PTSD and depressive symptoms are possibly overlapping, generated by common causes and mechanisms (death threats, loss of loved one, loss of property, threats to physical integrity of self, conditions of fear and helplessness).

Depressive symptoms are often integral to PTSD. However it was not clear for the majority of psychopathological cases whether depression occured in a parallel way within the first months following the traumatic exposure and the establishment of a PTSD diagnosis. Koenen et al. ${ }^{34}$ in their recent study supported that the PTSD comorbid with MDE has even a common genetic liability in men.

Regarding the duration of the symptoms, all cases of PTSD reported that their symptoms persisted for more than three months, so they could be identified as chronic cases. As far as the duration of PTSD symptoms concerns, several studies among refugees reported a persistence of symptoms composing a PTSD diagnosis, for more than six months, ranging from $52 \%$ for six months to $44 \%$ for one year and $4.8 \%$ for three years after the resettlement ${ }^{35-37}$.

The cause of this prolonged duration of PTSD symptoms, among the West Bank Palestinian sample could be explained by the continuous reactivation of trauma ${ }^{24,25}$. This phenomenon and it has already been described in several other studies among
Vietnam veterans and other special populations ${ }^{1,38-41}$. Solomon et al. ${ }^{38}$, and Kulka et al. ${ }^{1}$, reported those twenty years after the war of Vietnam, veterans were found to suffer at $31 \%$ from PTSD symptoms. Studies among Cambodian refugees resettled in Australia, have shown that twenty years after, continued to suffer from PTSD and other mental disorders related to trauma ${ }^{39}$. Kinzie et $a l^{40}$, have shown that the terrorist attack of September 11 in New York City, reactivated PTSD symptoms in refugees living there. In Israel already traumatized individuals were found to be vulnerable to newly occurring negative events, suffering from PTSD ${ }^{41}$.

Another interesting finding is that the rates of PTSD and PTSD/MDE showed almost no difference between genders, a finding not compatible with the existing literature on the epidemiology of PTSD and related comorbidity ${ }^{1-6}$. The continuous political violence and the consequences of the military occupation and series of violent acts of resistance are generating trauma related stress symptoms to everyone who is exposed, independent of gender ${ }^{24-27}$. In support of this assumption it is the finding that persons living in towns, villages or camps were found to suffer equally from PTSD and PTSD/MDE. According to Qouta ${ }^{44}$ the disruptive sociopolitical and economic atmosphere is dispersed in all demographic areas affecting everyone.

In the case of MDE higher number of males was found to suffer from lifetime MDE than females. The latter was also found in other epidemiological studies in Arab countries $^{42,43}$.

The Palestinian man is facing extreme difficult situations and responsibilities to feed the family members coping with extremely limited resources. In addition, the daily physical and psychological strains 
from the political oppression are resulting confusion and stress. The man is becoming unable to achieve the needs of his normal social position, feeling useless, secluded, abused and finally depressed ${ }^{44}$.

To answer the second question, the prevalence of PTSD comorbid with MDE among the refugees of our West Bank sample was found to be even higher than that of non refugees.

Thabet et al. ${ }^{45}$, studied a sample of 403 children living in four refugee camps in Gaza strip, the vast majority of them, they have experienced serious traumatic events compared to non refugee children. Being a refugee, displaced in your own country, is an additional burden despite that close family ties and support in the refugee camps still exist. Coming now to third question on the issue of suicidal behavior and diagnosis. It was found that the majority of males and females who reported an attempt of self harm, were comorbid cases of PTSD/MDE, a finding compatible of that reported by oth$\mathrm{ers}^{46}$. Undoubtly individuals with PTSD and MDE experience more severe psychiatric symptomatology, comp Several investigators have also reported the association of comorbid PTSD and MDE with greater risk of suicidal behaviour ${ }^{47,48}$. However the overall rate of suicidal attempts seems to be low compared to the size of the prevalence of psychopathology. Abdel-Khalek ${ }^{42}$, found in a cross-cultural study that death ideation was lower among Palestinians refugees in West Bank, than that among other Arabs living in Egypt Syria Lebanon and Kuwait. According to authors the low rates of suicidal ideation may reflect their adaptation to strife and violence.

The implications of comorbidity of PTSD and MDE beyond the risk of suicidality, are of great clinical importance especially in the area of clinical course and functioning of the suffering person. It has been demonstrated that comorbidity was associated with greater symptom severity, lower levels of functioning with worse clinical course $\mathrm{e}^{50,51}$.

In our study there were more PTSD symptoms in the comorbid group and the functioning level of the diagnosed PTSD/MDE cases could be characterized as impaired. It seems that comorbidity of PTSD and MDE is serious clinical entity.

Finally, as far as the fourth question is concerned, the delineation of possible differences in predictors of cases of PTSD, MDE and PTSD/MDE, revealed some similarity between predictors differentiating between depression alone (MDE) and no diagnosis and between comorbid PTSD with MDE and no diagnosis.

Being a refugee, having attempted suicide and using of psychotropic medication were found to be the same predictors for the diagnosis of MDE and PTSD/MDE. Our findings are consistent with those of $\mathrm{O}$ ' Donnel et al. ${ }^{11}$, for chronic PTSD comorbid with MDE. According to Breslau et al. ${ }^{16}$, the symptoms of depression and PTSD are possibly sharing the same vulnerability factors and thus have similar predictors. One additional variable "marital status" (being widowed or divorced), differentiated MDE alone from no diagnosis.

Place of residence, living in villages, where episodes of everyday violence are fewer (and having no income) was the predictors differentiating between PTSD alone and no diagnosis. Kessler et al. ${ }^{3}$, reported that high lifetime prevalence of PTSD was associated with lower socioeconomic status.

This study has several limitations. Due to inadequate funding, less common mental disorders were excluded from an extended clinical investigation. No reliability study of case identification during the field inter- 
views was possible due to the local circumstances e.g taping interviews and interrater diagnostication. Additionally no validity study of the SCID module for MDE diagnosis was also conducted. Possible transcultural fallacies in detection and interpretation of psychopathologic symptoms by the use of Western derived screening instrument are to be taken into consideration. The cross-sectional design of this study precludes causal inferences. Moreover this study is limited to one half of the Palestinian Authority area, so the results may not fully generalizable to Gaza strip population, living in extreme socioeconomic and political harshness. However it should be noted the overall willingness of the respondents to openly accept the interviewer and discuss their traumatic experiences, although there were cases of mistrust due to the general atmosphere.

In sum, this study provides evidence that an adult population under continuous mass violence and apprehension are more likely to suffer from PTSD and depressive symptoms than others living in rather safe and stable conditions. From clinical point of view, the morbidity detected in the West Bank sample can be characterized as severe. Additionally the chronicity of PTSD symptoms is influencing the functional capacity of the suffering individual. Further studies of longitudinal type on the course of PTSD and MDE could reveal etiological pathways, coping mechanisms and possible modes of survival.

\section{Acknowledgements}

The authors would like to express their deep appreciation to all West bank participants of this study and the local Palestinian Authorities for their valuable help.

\section{References}

1. Kulka R, Schlenger W, Fairbank J, Hough R, Jordan B, Marmar C, et al. Trauma and the Vietnam War generation. New York: Brunner/Mazel; 1990.

2. Breslau N, Kessler RC, Chilcoat HD, Schultz LR, Davis GC, Andreski P. Trauma and posttraumatic stress disorder in the community: the 1996 Detroit Area Survey of Trauma. Arch Gen Psychiatry 1998; 21(2): 626-632.

3. Kessler RC, McGonagle KA, Zhao S, Nelson CB, Hughes M, Eshleman S, et al. Lifetime and 12 month prevalence of DSM III R psychiatric disorders in the United States. Results from the National Comorbidity Survey. Arch Gen Psychiatry 1994; 51: 8-19.

4. Kessler RC, Sonnega A, Bromet E, Hughes M, Nelson CB. Post-traumatic stress disorder in the National Comorbidity Survey Replication. Arch Gen Psychiatry 1995; 52: 1048-1060.

5. Kessler RC, Chiu WT, Demler O, Merikangas KR, Walters EE. Prevalence, severity and comorbidity of 12month DSM IV disorders in the National Comorbidity Survey Replication. Arch Gen Psychiatry 2005; 62: 617-627.

6. Creamer M, Burgess P, Mc Farlane AC. A posttraumatic stress disorder: findings from the Australian National Survey of Mental Health Well-Being. Psychol Med 2001; 31: 1237-1247.

7. Breslau N, Davis GS, Andreski P, Peterson E. Traumatic events and posttraumatic stress disorder in an urban population of young adults. Arch Gen Psychiatry 1991; 48: 216-222.

8. Bleich A, Koslowsky M, Doler A, Lever B. Posttraumatic stress disorder and depression. Br J Psychiatry 1997; 170: 479-482.

9. Shalev AY, Freedman S, Peri T, Branders D, Sahar T, Orr SP, et al. Prospective study of posttraumatic stress disorder and depression following trauma. Am J Psychiatry 1998; 155: 630-637.

10. Franklin CL, Zimmerman M. Post traumatic Stress Disorder and Major Depressive Disorder: Investigating the role of overlapping symptoms in diagnostic comorbidity. J Nerv Ment Dis 2001; 189: 548-551.

11. O’ Donnel M, Creamer M, Pattison P. Posttraumatic stress disorder and depression following trauma: understanding comorbidity. Amer J Psychiatry 2004; 161: 1390-1396.

12. Kotler M, Iancu I, Efroni R, Amir M. Anger, impulsivity, social support, and suicide risk in patients with posttraumatic stress disorder. J Nerv Ment Dis 2001; 189:162-167. 
13. Oquendo MA, Friend JM, Halberstam B, Brodsky B, Burke A, Grunebaum M, et al. Association of comorbid posttraumatic stress disorder and major depression with greater risk for suicidal behavior. Am J Psychiatry 2003; 160: $580-582$.

14. Ferrada-Noli M, Asberg M, Ormstad K, Lundin T, Sundbom E. Suicidal behavior after severe trauma, part 1: PTSD diagnoses, psychiatric comorbidity, and assessments of suicidal behavior. J Trauma Stress 1998; 11: 103-112.

15. Bromet E, Sonnega A, Kessler RC. Risk factors for DSM III R Post Traumatic Stress Disorder: findings from the National Comorbidity Survey. Am J Epidemiol 1998; 147: 357-361.

16. Breslau N, Davis GC, Peterson EL, Schultz LR. A second look at comorbidity in victims of trauma: the posttraumatic stress disorder major depression connection. Biol Psychiatry 2000; 48: 902-909.

17. Davidson JRT, Kudler HS, Saunders WB, Smith SD. Symptom and morbidity patterns in World War II and Vietnam veterans with post traumatic stress disorder. Compr Psychiatry 1990; 31: 162-170.

18. Krammer TL, Lindy JD, Green BL, Grace MC, Leonard AC. The commorbidity of post-traumatic stress disorder and suicidality in Vietnam veterans. Suicide Life Threat Beh 1994; 24: 58-67.

19. Maes M, Mylle J, Delmeire L, Altamura C. Psychiatric morbidity and comorbidity following accidental manmade traumatic events: incidence and risk factors. Eur Arch Psychiatry Clin Neurosci 2000; 250: 156-162.

20. Momartin S, Silove D, Manicavasagar V, Steel Z. Comorbidity of PTSD and depression: association with trauma exposure, symptoms, severity and functional impairment in Bosnian refugees. J Affect Disord 2004; 80: 231-238.

21. Mollica RF, McInnes K, Poole C, Tor S. Dose-effect relationships of trauma to symptoms of depression and post-traumatic stress disorder among Cambodian survivors of mass violence. Brit J Psychiatry 1998; 173: 482-488.

22. Mollica R, Caridad KR, Massagli M. Longitudinal study of posttraumatic stress disorder depression and changes in traumatic memories over time in Bosnian refugees. J Nerv Ment Dis 2007; 195: 572-579.

23. Marshall GN, Schell TL, Elliot M, Berthold SM, Chun CA. Mental health of Cambodian refugees 2 decades after resettlement in the United states. JAMA 2005; 294 : 571-579.

24. BãTselem, the Israel Information Center for human rights in the occupied territories. Prisoners of peace: Administrative detention during Oslo process. Report No 16 Jerusalem: Tselem, 1997.
25. Murad I. Psychiatry in the Palestine Authority: legal ethical and forensic issues. Isr J Psychiatry Relat Sci 1999; 36: 65-74.

26. Punamaki RL, Komproe I, Quota S, Elmarsi M, De Jong JT. The role of peritraumatic dissociation and gender in the association between trauma and mental health in a Palestinian community sample. Amer J Psychiatry 2005; 162: 545-551.

27. De Jong JTV, Komproe IH, Van Ommeven M, El Mavsi M, Araya M, Khalen N, et al. Lifetime events and Posttraumatic Stress Disorders in a Postconflict settings. JAMA 2001; 286: 551-562.

28. Karam EG, Howard DB, Karam AN, Ashkar A, Shaaya M, Melhem N, et al. Major depression and external stressors: the Lebanon wars. Eur Arch Psychiatry Clin Neurosci 1998; 248: 225-230.

29. Elbedour S, Onwegbuzie A, Ghannam J, Whitcome J, Abuhein F. Post-traumatic stress disorder, depression and anxiety among Gaza strip adolescents in the wake of the second Uprsising (Intifada). Child Abuse and Neglect 2007; 31: 719-729.

30. Khamis V. Post-traumatic stress and psychiatric disorders in Palestinians adolescents following intifada-related injuries. Soc Sci Med 2008; 67:1199-1207.

31. First MB, Gibbon M, Spitzer RL, Williams JBW. Structured Clinical Interview for Axis I DSM IV Disorders-Patient Edition. Biometrics Research Department, New York State Psychiatric Institute, New York, 1996.

32. SPSS Inc. SPSS 11.0 for Windows, users guide. Chicago SPSS, 1999.

33. Green BL, Lindy JD, Grace MC, Leonard AC. Chronic posttraumatic stress disorder and diagnostic comorbidity in a disaster sample. J Nerv Ment Dis 1992; 180: 760-766.

34. Koenen K, Fu Q, Ertel K, Lyons M, Eisen S, True $\mathrm{W}$, et al. Common genetic liability to Major Depression and Posttraumatic Disorder in men. J Affective Disorders 2008;105: 109-115.

35. Kinzie JD, Sack W, Angell R, Clarke G, Ben R. A three-year follow up of Cambodian young people traumatized as children. J Am Acad Child Adolesc Psychiatry 1989; 28: 501-504.

36. Weine SM, Vojvode D, Becker DF, McGlashan TH, Hodzic E, Laub D, et al. PTSD symptoms in Bosnian refugees 1 year after resettlement in the United Statets. Am J Psychiatry 1998; 155: 562-564.

37. Steel Z, Silove DM, Bird K. Pathways from war trauma to posttraumatic stress symptoms among Tamil asylum seekers, refugees and immigrants. J Trauma Stress 1999; 12: 421-435. 
38. Solomon Z, Gorb R, Bleich A, Grupper D. Reactivation of combat-related PTSD. Am J Psychiatry 1987; 144: 51-55.

39. Marshal GN, Shell TL, Eliot MN, Berthold SM. Mental health of Cambodian refugees 2 decades after resettlement in the United States. JAMA 2005; 294: 571-579.

40. . Kinzie JD, Boehnlein JK, Riley C, Sparr L. The effects of September 11 on traumatized refugees: Reactivation of PTSD. J Nerv Ment Dis 2002;199: 437-471.

41. Toren P, Wolmer L, Weizman R, Magel-Vandi O, Loan N. Retraumatization of Israel civilians during a reactivation of the Gulf war treat. J Nerv Ment Dis 2002; 190: 43-45.

42. Okasha A, Khalil AH, El Fiky MR, Ghanen M, Abdel Hakeem R. Prevalence of depressive disorders in a sample of rural and urban Egyptian communities. Egyptian J Psychiatry 1988; 2:167-181.

43. Khatwa S, Abdon M. Adult depression in Al Eskandaria, Egypt. Journal of Egyp. Public Health Assoc 1999; 74: 333-352.

44. Quota S. Trauma violence and mental health: The Palestinian experience. Amsterdam: Doctoral Dissertation. Amsterdam. Vrije Universiteit, 2003.

45. Thabet AA, Yahua A, Vostanis P. Comorbidity of PTSD and depression among refugee children during war conglict. J Child Psychol and Psychiatry 2004; 45: 533-542.

46. Davidson JRT, Hughes D, Blazer D, George LK. Posttraumatic stress disorder in the community: an epidemiological study. Psychol Med 1991; 21: 713-721.
47. Oquendo M, Friend J, Halberstam B, Brodsky B, Burke A, Grunebaum M, et al. Association of comorbid Post traumatic Stress Disorder and Major Depression with greater risk for suicidal behavior. Psychiatry 2003; 160: 580-582.

48. Cougle J, Resnick H, Kilpatrick D. PTSD, depression and their comorbidity in relation to suicidality: cross-sectional and prospective analyses of a national probability sample of women. Depress Anxiety 2009; 1151-1157.

49. Abdel-Khalek AM, A1-Arja NS, Abdalla T. Death obsession in Palestinians. Death Stud 2006; 30: 203-215.

50. Shalev AY, Freedman S, Peri T, Brandes D, Sahar T, Orr S, et al. Prospective study of posttraumatic stress disorder and depression following trauma. Amer J Psychiatry 1998; 155: 630-637.

51. Gaudiano B, Zimmerman M. Does comorbidity post-traumatic stress disorder affect the severity and course of psychotic major depressive disorder? J Clin Psychiatry 2010; 71: 442-450.

Address for correspondence:

Professor Michael G. Madianos

Department of Mental Health \& Behavioral Sciences

Social Psychiatry Unit

School of Health Sciences

University of Athens

42 Davaki-Pindou Str, Zografou 157-73

Athens, Greece

Tel. / Fax ++302107481174

E-mail: madianos@nurs.uoa.gr 